\title{
Design characteristics of Curved Blade Aerator w.r.t. aeration efficiency and overall oxygen transfer coefficient and comparison with CFD modeling
}

\author{
L.B. Bhuyar ${ }^{1}$, S.B. Thakre ${ }^{1 *}$, N.W. Ingole ${ }^{2}$ \\ ${ }^{1 *}$ P.R.M. Institute of Technology \& Research, Badnera, Amravati (M.S), India 444701 \\ ${ }^{2}$ Principal, IBSS College of Engineering, Ghatkheda, Amravati (M.S), India 444605 \\ "Corresponding Author: e-mail:sbthakre2007@rediffmail.com,sbthakre2007@gmail.com
}

\begin{abstract}
The main objective of this work is to design a high efficiency curved-blade-surface mechanical aerator for oxidation ditch, which is used to treat municipal and domestic sewage. Aeration experiments were conducted in oxidation ditch made up of mild steel sheets to study the design characteristics of curved blade surface mechanical aerator. The paper critically examines six different configurations of aerators, which were developed, fabricated and tested in the laboratory for its various dynamic parameters, such as diameter of aerators (D), speed (N) and immersion depth (h). Out of the different configurations tested, the curved blade rotor (CBR) emerged as a potential aerator with blade tip angle of $47^{\circ}$. The overall oxygen transfer co-efficient $\left(\mathrm{K}_{\mathrm{L}} \mathrm{a}\right)$ was observed to be as high as $10.33 \mathrm{~h}^{-1}$ and the optimum aerator efficiency (AE) was found to be $2.269 \mathrm{kgO}_{2} / \mathrm{kWh}$. The standard aeration efficiency (SAE) of CBR was observed to be higher as compared to other aerators used for oxidation ditch process. Dimensional analysis was used to develop equations that describe the aerator's behavior. Further, a CFD model is also developed for better understanding of the process that takes place inside the ditch. To prepare it 3D and steady flow, k-e turbulence model of flow was used and the simulation runs were carried out for one phase model to generate the data so as to compare it with experimentally observed values.
\end{abstract}

Keywords: Oxidation ditch, dissolved oxygen, aerator, overall oxygen transfer coefficient, aeration efficiency, CFD

\section{Introduction}

Oxygen transfer, the process by which oxygen is transferred from the gaseous to liquid phase, is a vital part of the waste-water treatment process (Metcalf and Eddy, 2001). Due to low solubility of oxygen and consequent low rate of oxygen transfer, sufficient oxygen to meet the requirement of aerobic waste does not enter through normal surface air water interface. To transfer the large quantities of oxygen that are needed, additional interfaces are created by employing aeration process. The creation of additional interfaces enhances the rate of oxygen transfer so that the dissolved oxygen level gets raised to allow aerobic bacteria to remove biochemical oxygen demand of the effluent. To provide the required amount of oxygen, an aeration system is always needed. Aeration is usually the single largest cost in a waste water treatment system comprising as much as $50-90 \%$ of the total energy requirements of a secondary waste-water treatment plan (Wasner et al, 1977). Dissolved oxygen (DO) concentration is one of the most important water quality parameters affecting the quality of waste-water. Various types of aeration systems have been developed over the years to maintain the desired level of DO concentration in the waste water as an effort to improve the energy efficiency of the oxygen mass transfer process. The three basic categories of aeration methods are (Thakre et al, $2008 \mathrm{a}$ ): -

1) Surface or mechanical aeration method, which increases interfacial area by spraying water droplet into the air.

2) Diffused aeration method, which release air bubbles beneath the surface of water.

3) Combined and turbine aeration methods, which introduced large air bubble into water and reduce their sizes mechanically. 
Out of these three, the mechanical surface aerators are widely used because they offer better efficiency as well as convenience in operation and maintenance (Rao and Kumar. 2007). Further, oxygen transfer rate from gas to liquid phase is dependent on various factors for given method of aeration such as dynamic variables like speed, mixing intensity and turbulence, geometrical parameters like size and number of blades, depth of flow etc and physicochemical properties of the liquid. Even though the designer or operator can fix or control some of these parameters, successful design requires the knowledge of the effect of all such parameters on reaeration rate. A wide variation in performance of aerators in terms of standard aeration efficiency was found, viz. "Taiwanese" aerator $\left(1.17 \mathrm{kgO}_{2} / \mathrm{kWh}\right)$, "Japanese" aerator $\left(1.03 \mathrm{kgO}_{2} / \mathrm{kWh}\right)$ and Auburn university design $(2.25 \mathrm{kgO} / 2 \mathrm{kWh})$ (Boyd and Watten, 1989; Boyd, 1998). For proper aeration, i.e., proper mixing of DO throughout the water volume, American public health association (APHA, 1985) mentioned that the power-to-water volume ratio should lie within $0.01-0.04 \mathrm{~kW} / \mathrm{m}^{3}$. However, the water volume used in the aeration studies conducted so far has not been quantified properly. In the field of wastewater treatment, many investigators have successfully made use of the theory of dimensional analysis and obtained optimal geometric similarity of horizontal rotor aerators under different conditions (Eckenfelder, 1956; Horvath, 1984; Ognean, 1993; Zolkarnik, 1976; Schmidtke and Horvath 1977) presented the occurrence of scale effects due to the Reynolds and the Froude's laws of the aeration performance under similar geometric conditions. The criterion of power per unit volume was found to be very useful in geometrically similar systems for scale-up of horizontal rotor aerators (Rao, 1999).

Application of the aeration phenomena in waste-water treatment and aquaculture has been different. The needs of the aquaculture industry, however, are different than those of the waste-water treatment industry. In aquaculture applications, the dissolved oxygen concentration must be much higher than that in waste-water treatment (Cansino et al., 2004). Boyd and Watten (1989) summarized the importance of the dissolved oxygen concentration in aquaculture. They have shown that most warm water species can tolerate concentrations as low as $2-3 \mathrm{mg} / \mathrm{l}$ of dissolve oxygen, and many cold-water species can tolerate $4 \mathrm{or} 5 \mathrm{mg} / \mathrm{l}$. The problem is that aquatic organisms eat and grow better and are healthier when the dissolved oxygen concentration is at or near saturation. But in case of waste-water treatment the dissolved oxygen concentration of $2 \mathrm{mg} / \mathrm{l}$ is sufficient to carry out the treatment process.

Several aerators for oxidation ditches have already been developed. It is necessary to investigate the efficiency of aerator that has been used from the point of view of energy consumption. Questions such as best number of blades used in the design, the necessary number of blades, the shape of the blades, the relevant geometric parameters involved in the mass transfer, which are interesting to study in order to determine the optimum aeration efficiency have yet not been determined.

To design high efficiency surface aerator it is necessary to identify the parameters that are relevant to the oxygen transfer phenomena and to investigate the best way to optimize the aeration efficiency value. This means that the value of overall oxygen transfer coefficient $\left(\mathrm{K}_{\mathrm{L}} \mathrm{a}\right)$ must be increased and the power consumption must be kept at the same level or diminished.

Therefore, the objective of the present research work is to design a high efficiency curved blade surface mechanical aerator for oxidation ditch and to determine optimum aeration efficiency, which could be used to treat municipal and domestic sewage with minimum power consumption. Secondly, to generate a model based on computational fluid dynamic (CFD) so as to match the results generated by physical model with that of CFD model. The experimental apparatus of the oxidation ditch with different aerators was designed, fabricated and installed in the research laboratory of the institute.

\section{Materials and Methods}

A simplified schematic sketch of experimental setup used for present study is shown in Figure 1. The aeration experiments were conducted in Oxidation Ditch (OD) of dimension $2.5 \mathrm{~m} \times 0.35 \mathrm{~m} \times 0.2 \mathrm{~m}$. The oxidation ditch used for experimentation was made up of mild steel sheet and was situated above the ground with the supports provided at front, rear and middle of the ditch. Arrangements were made during fabrication of ditch, for varying the depth of immersion of the rotor. Gears and sprocket were mounted on rotor shaft and d.c. motor, respectively. Chain drive was preferred over belt drive to avoid slip during the power transmission. The motor was connected to variable speed controller to obtain variation in the speed of rotation. The experimental setup mainly consists of an Oxidation Ditch, D.C. motor (0.25 H.P, 1 Amp) with variable speed controller, digital wattmeter (range 0-200W), dissolve oxygen meter, thermometer, and digital tachometer.

2.1Fabrication of aerator rotor: CBR was fabricated using impeller fans made up of fiber and are used in centrifugal pump, which are available in the market in various sizes. A $23 \mathrm{~cm}$ in diameter fan disc with a 12 small fins of size $5 \mathrm{~cm} \times 3 \mathrm{~cm}$ mounted on it was selected to configure an aerator so that the effective diameter of the disc becomes $26 \mathrm{~cm}$. A fiber pipe of 1.5 inch, 2 inch, 3 inch of appropriate length was cut into pieces such that 24 equal strips of length $14 \mathrm{~cm}$ and $4 \mathrm{~cm}$ width were yielded from each pipe. The different diameter pipes were used so as to obtain the change in blade tip angles. A pair of fan disc was taken and the strips thus fabricated were screwed on projected fins of the fan discs as shown in Figure 2.

Figure 2 represents the side view of the aerator representing the fin dimensions for a fiber pipe of 2 inch diameter, which yielded the blade tip angle of 47 degrees. $1.1 \mathrm{~cm}$ indicates the projected length of the fin thus obtained after fabrication. Since optimum oxygen transfer was observed with 47 degree blade tip angle, therefore this configuration of aerator is represented in the figure. 

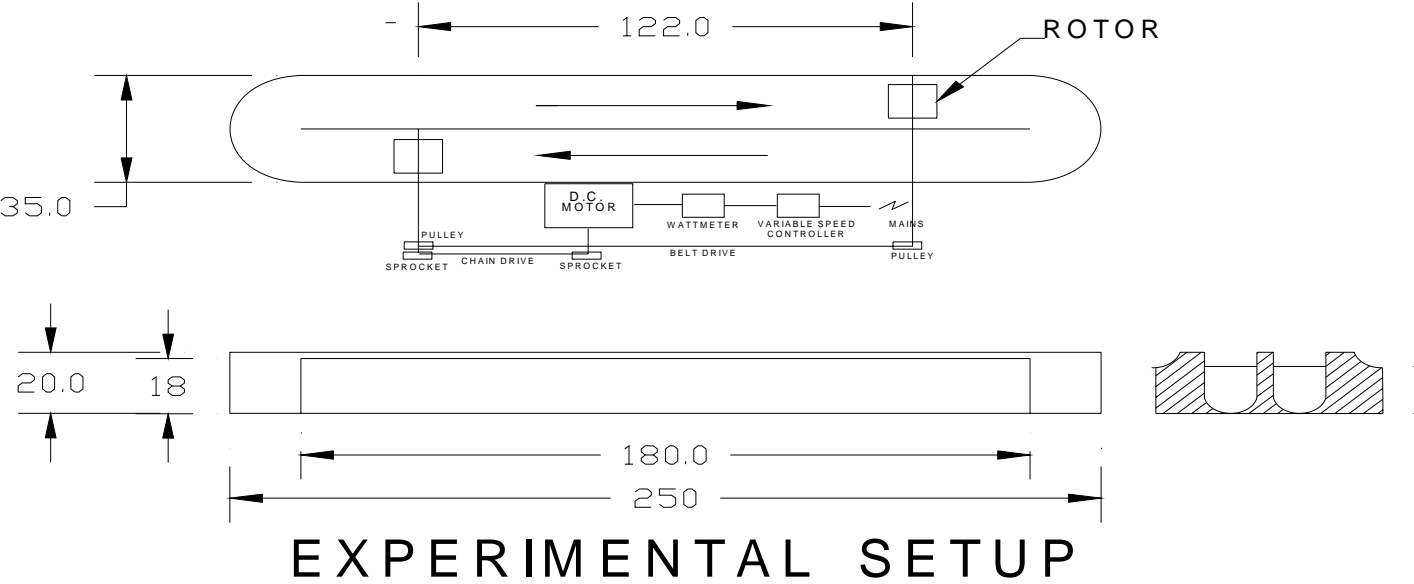

Figure 1. Experimental setup for oxidation ditch, aerators and driving mechanism

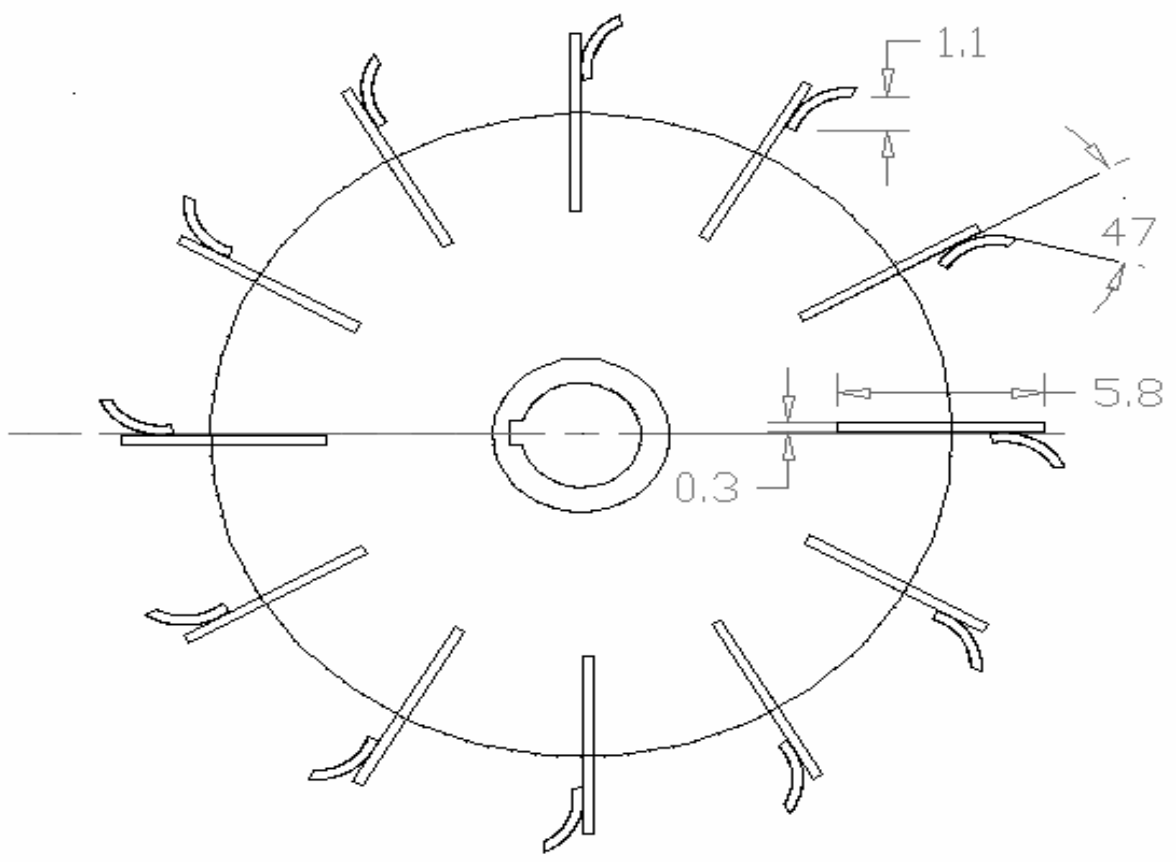

Figure 2. Side view of the curved blade aerator (All dimensions in $\mathrm{cm}$ )

The fiber pipe of 1.5 inch and 3 inch diameter were used to get different blade tip angles. By using above diameter pipes, blade tip angle of 27 degrees and 60 degrees were obtained. Since these configurations did not prove to be the best for the optimum aeration efficiency, therefore the figures pertaining to these configurations are not provided.

The strips were screwed in such a fashion that the projected length of the strip over the disc fins was $1.5 \mathrm{~cm}$. Therefore the effective diameter of rotor thus fabricated amounts to $29 \mathrm{~cm}$ with 12 blades (fiber strips) mounted on each aerator rotor. The overall dimensions are shown in Figure 3.This assembly of aerator was fastened tightly to the shaft and then fixed in the bearings provided on the collars of the oxidation ditch.

The depth of immersion (DOI) was varied from $4.8 \mathrm{~cm}$ to $7.2 \mathrm{~cm}$ and the speed was varied from $36 \mathrm{rpm}$ to $60 \mathrm{rpm}$. The performance was evaluated for each kind of configuration of aerator rotor by changing various parameters such as, aerator blade tip angles, speeds, and depth of immersion with respect to power consumption. 


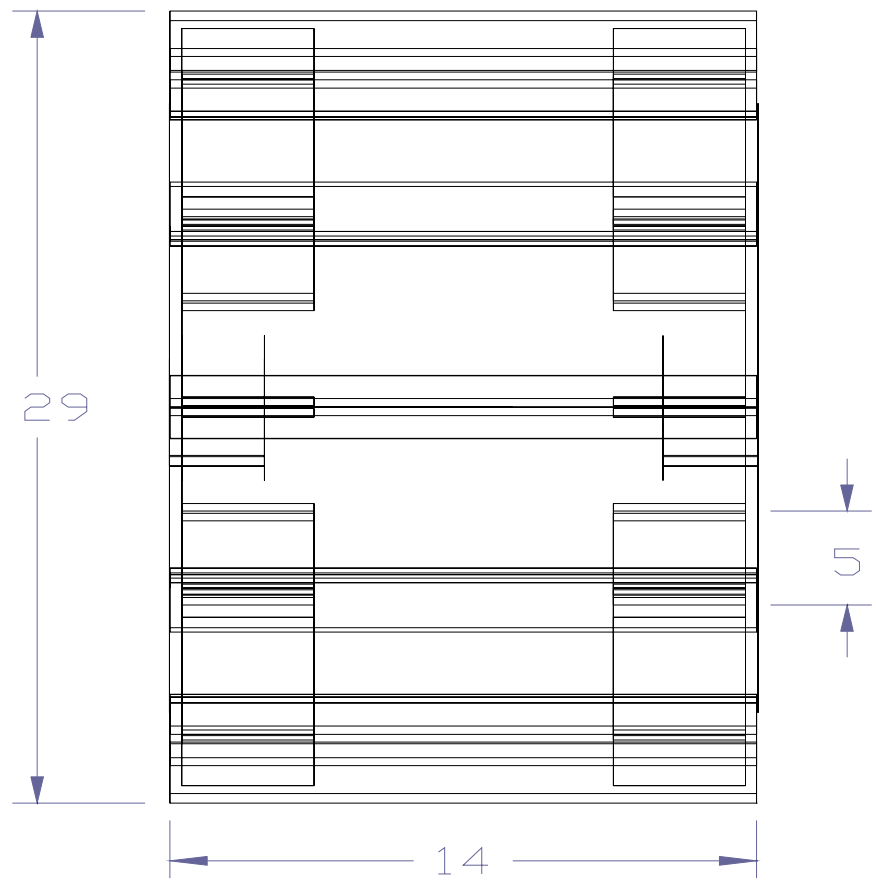

Figure 3. Front View of curved blade aerator (All dimensions in $\mathrm{cm}$ )

\section{Aeration Test}

The deoxygenating-oxygenation procedure used was the non-steady-state reaeration test (Moulick, et al 2005; Thakre et al, 2009). The test water was deoxygenated with $10 \mathrm{mg} / \mathrm{L}$ of sodium sulphite, cobalt chloride was not used during test since it is considered hazardous to human health (Cancino, 2004). After maintaining DO between $0.0-0.1 \mathrm{mg} / \mathrm{L}$ for about 5 minutes, both the aerator were put in operation at the same moment and at the same rotational speed and immersion depth. Increase in DO concentration was measured by DO probe at the surface of water and at the half depth from the surface. The readings were taken at equal time intervals until DO increased from $0 \%$ saturation to at least $90 \%$ saturation. The dissolved oxygen saturation concentration $\left(\mathrm{C}_{\mathrm{s}}\right)$ used for calculating the $\mathrm{K}_{\mathrm{L}}$ a was estimated using the highest dissolved oxygen concentration from each test.

\section{Results and Discussion}

Out of the various factors which may affect aeration or dissolve oxygen level, time of aeration, depth of immersion, speed of aerator, and blade tip angle mounted on the aerator, are mainly considered for performance evaluation of an aerator. For every set of observation, overall oxygen transfer coefficient $\mathrm{K}_{\mathrm{L}} \mathrm{a}$, which is a measure of aeration, is computed and its behavior is studied with respect to other variables, keeping other variables constant at that time. $\mathrm{K}_{\mathrm{L}} \mathrm{a}$, the overall oxygen transfer coefficient is the rate of oxygen transfer for a unit saturation deficit and it is constant for particular system of aeration. Assessment of overall oxygen transfer coefficient of an aeration system is one of the most important factors. Underestimating the oxygen transfer rate results in over designed system, which may be energy intensive and expensive to operate. On the other hand, overestimating the oxygen transfer rate results in inadequate oxygen supply, which in turn, reduces efficiency.

\subsection{Mathematical model for measurement of overall oxygen transfer co-efficient ( $K_{L} a$ )}

For treatment of domestic and industrial waste, mathematical modeling is done. The engineers wish to fit an analytical function based on observed data or to evaluate the parameters of some prescribed functional representation. The eight types of equations are used and out of these equations, linear fit equation is adopted for mathematical modeling in the present study. Aeration is transfer of air or oxygen in the water (Kumar, 1991; Thakre et al. 2008b). The oxygen transfer through water is governed by Fick's Law of diffusion and is a liquid film controlled process. In aeration, the rate of oxygen transfer was expressed earlier as,

$$
d c / d t=\mathrm{K}_{\mathrm{L}} \cdot \mathrm{a} \cdot\left(\mathrm{C}_{\mathrm{S}}-\mathrm{C}_{\mathrm{t}}\right)
$$


where, $K_{L} a$ is the rate of oxygen transfer for saturation deficit. Therefore, this is referred as measurement of aeration and it forms a good basis of studying the behavior under various variables. This is employed in the study in the unit of $\mathrm{min}^{-1} \mathrm{or} \mathrm{hr}^{-1}$. The rate of oxygen transfer equation was converted into

$$
C_{(t+h)}=C_{t} \cdot e^{-\mathrm{K}_{\mathrm{L}} \cdot \mathrm{a} \cdot \mathrm{h}}+C_{S}\left(1-e^{-\mathrm{K}_{\mathrm{L}} \cdot \mathrm{a} \cdot \mathrm{h}}\right)
$$

This is comparable to the equation of straight line of the form:

$$
\mathrm{Y}=\mathrm{m} \cdot \mathrm{X}+\mathrm{A}
$$

Thus, if a plot is obtained in between $C_{(t+h)}$ and $C_{t}$, it would yield a straight line and slope of this line (m) represent the value of $e^{-\mathrm{K}_{\mathrm{L}} \cdot \mathrm{ah}}$ from which $\mathrm{K}_{\mathrm{L}} \cdot \mathrm{a}$ can be calculated. Similarly, the intercept on $\mathrm{Y}$-axis (A) represents the term $C_{S}\left(1-e^{-\mathrm{K}_{\mathrm{L}} \cdot \mathrm{a} \cdot \mathrm{h}}\right)$ from which the value of $C_{S}$ can be known. Thus it clearly indicates that in order to determine the value of $\mathrm{K}_{\mathrm{L}} \cdot \mathrm{a}$, it must be carried out at a uniform interval of time.

In the present study the curves have been drawn between $C_{(t+h)}$ against $C_{t}$ and time interval $\mathrm{h}$ is taken as 15 minutes. The slope of this line is known and the value of overall oxygen transfer coefficient $\mathrm{K}_{\mathrm{L}} \cdot \mathrm{a}$ is calculated. This method is used for calculation of performance of different aerators. The plot between $C_{(t+h)}$ and $C_{t}$ is obtained for different configuration of rotor aerator at different speeds of 36, 42, 48 and $60 \mathrm{rpm}$. The data generated from different rotors followed different curves and indicated different values of $\mathrm{K}_{\mathrm{L}} \mathrm{a}$ and aeration efficiency.

\subsection{Variation of $D O$ with Time for various depth of immersion}

We refer to figure 4, which illustrates that the increase in DO concentration is very high in first 15 minutes, and then it gradually attains a saturation value pertaining to the performance of the respective aerator. It is observed that the maximum increase in DO concentration, that is, from $0.0 \mathrm{mg} / \mathrm{L}$ to $8.2 \mathrm{mg} / \mathrm{L}$ is attained by CBR aerator when the blade tip angle is 47 degrees and the depth of immersion is $5.5 \mathrm{~cm}$. All the curves were plotted at $48 \mathrm{rpm}$ aerator speed. The literature cited by the author reveals that the optimum performance is generally obtained at blade angle of 45 degrees. Therefore the above blade angle is chosen.

\subsection{Variation of $K_{L} a$ and power for various blade angles and speed}

From Figure 5, it can be observed that the variation of $\mathrm{K}_{\mathrm{L}} \mathrm{a}$ and power for various blade angles and speed, with respect to CBR aerator and considering the depth of immersion $5.5 \mathrm{~cm}$ is an optimum value. It is very clear from figure that as the power and speed increases the corresponding values of $\mathrm{K}_{\mathrm{L}} \mathrm{a}$ also increases. It is also evident from the figure that at a speed of $48 \mathrm{rpm}$ the power requirement is observed to be in the medium range that is $73.8 \mathrm{~W}$, whereas there is a considerable increase in value of $\mathrm{K}_{\mathrm{L}} \mathrm{a}$ in the tune of $10.33 \mathrm{~h}^{-1}$. As the power consumption decreases below $73.8 \mathrm{~W}$, the value of $\mathrm{K}_{\mathrm{L}} \mathrm{a}$ also decreases accordingly, which further decreases the aeration efficiency, which is not acceptable as per the values quoted by the researchers.

When the power consumption increases beyond $73.8 \mathrm{~W}$, there is a marginal increase in $\mathrm{K}_{\mathrm{L}} \mathrm{a}$ value, but aeration efficiency drops sharply from $2.269 \mathrm{kgO}_{2} / \mathrm{kWh}$ to $1.37 \mathrm{kgO}_{2} / \mathrm{kWh}$. As the speed of CBR aerator is increased from $48 \mathrm{rpm}$ to $60 \mathrm{rpm}$, it is observed that splashing of wastewater outside the ditch takes place, which deteriorates the surrounding atmosphere and thereby causing problems for working people present at the plant. This may also create problems in driving mechanism as the motor is mounted below the ditch. 


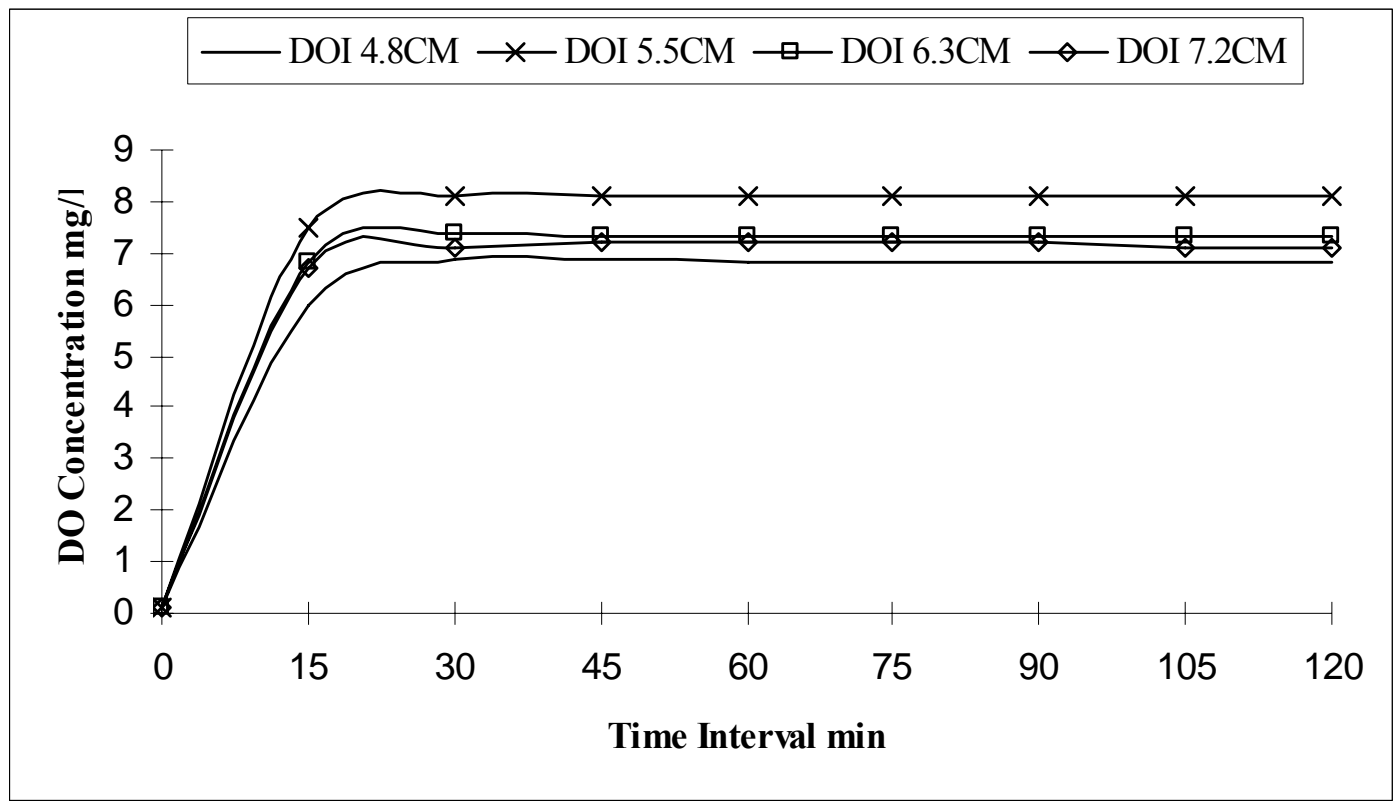

Figure 4.Variation of DO with Time for different depth of immersion and blade tip angle of $47 \mathrm{deg}$.

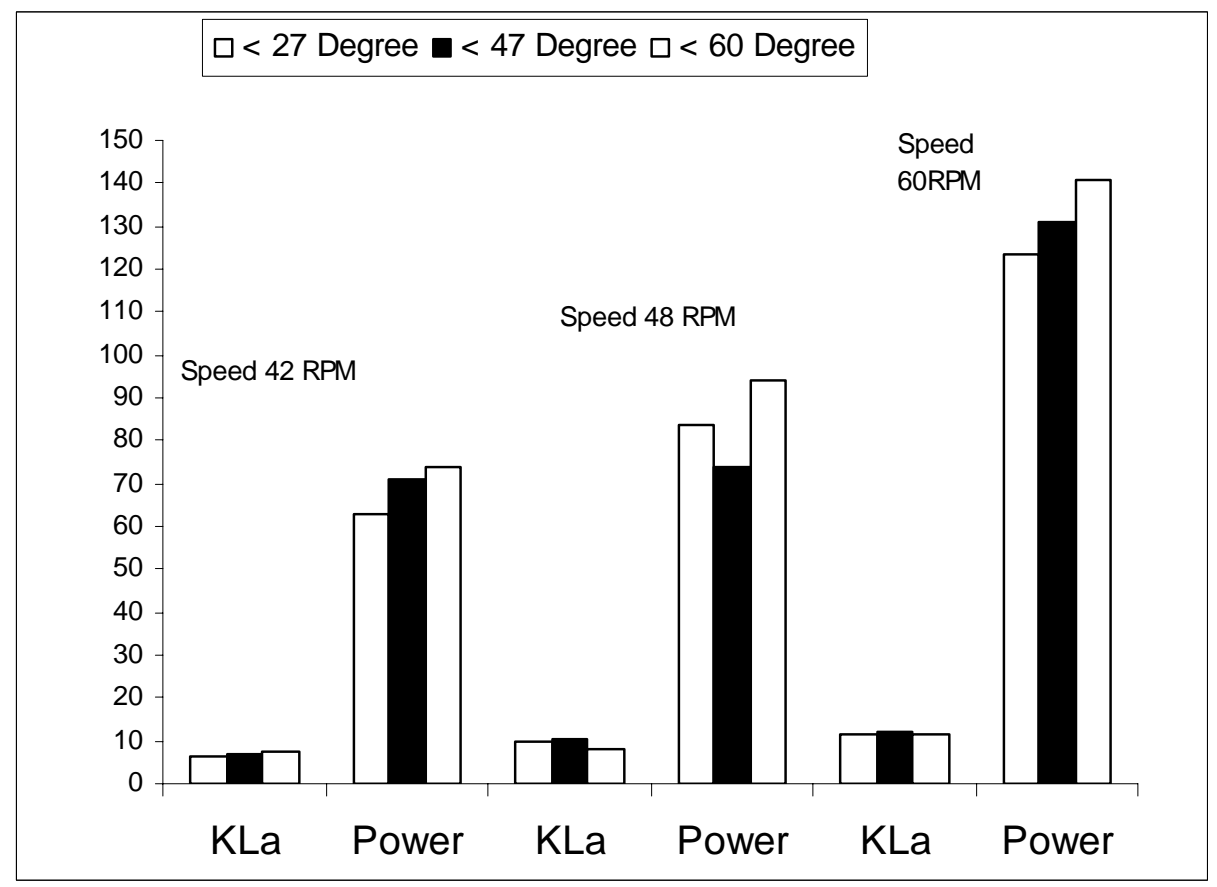

Figure 5. Variation of $\mathrm{K}_{\mathrm{L}} \mathrm{a}$ and Power for CBR for various Blade angles and Speeds, depth of immersion $5.5 \mathrm{~cm}$

\subsection{Variation in DO for various blade tip angle with Time}

The variation in DO for various blade tip angle with time is shown in Figure 6 . The figure 6 represents the curves plotted at 42 $\mathrm{rpm}$ and $5.5 \mathrm{~cm}$ depth of immersion. Three types of blade tip angles were tested, which suggest that maximum DO concentration is achieved when the blade tip angle is at 47 degrees. With this configuration, DO level of $8.2 \mathrm{mg} / \mathrm{L}$ is attained in $45 \mathrm{minutes}$ and thereafter the DO concentration curve remains constant which indicates that the saturation deficit of oxygen is met. 


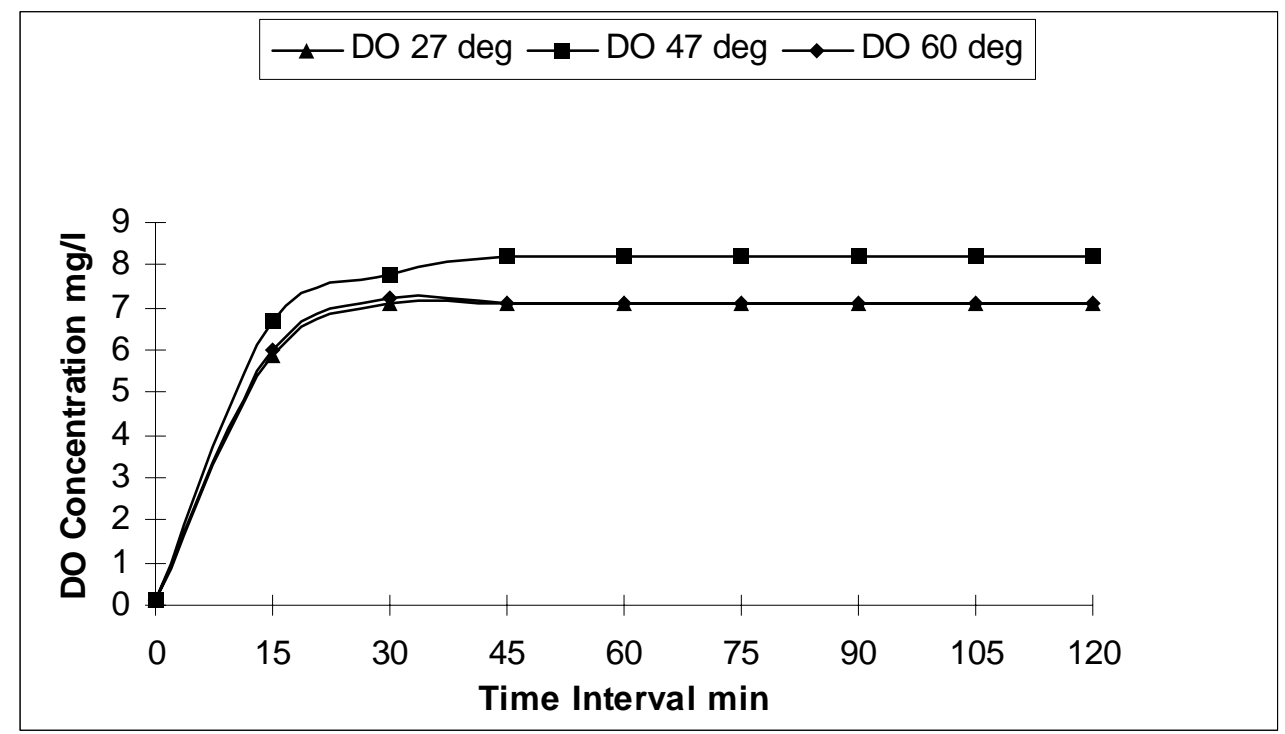

Figure 6. Variation of DO Vs Time for various angles of CBR, speed $42 \mathrm{rpm}$ and DOI- $5.5 \mathrm{~cm}$

Figure 7 and Figure 8 represent the same plot as above follow the similar trend as that of Figure 6. Combined analysis of all the three figures reveals that the optimum performance is recorded at blade tip angle of 47 degrees.

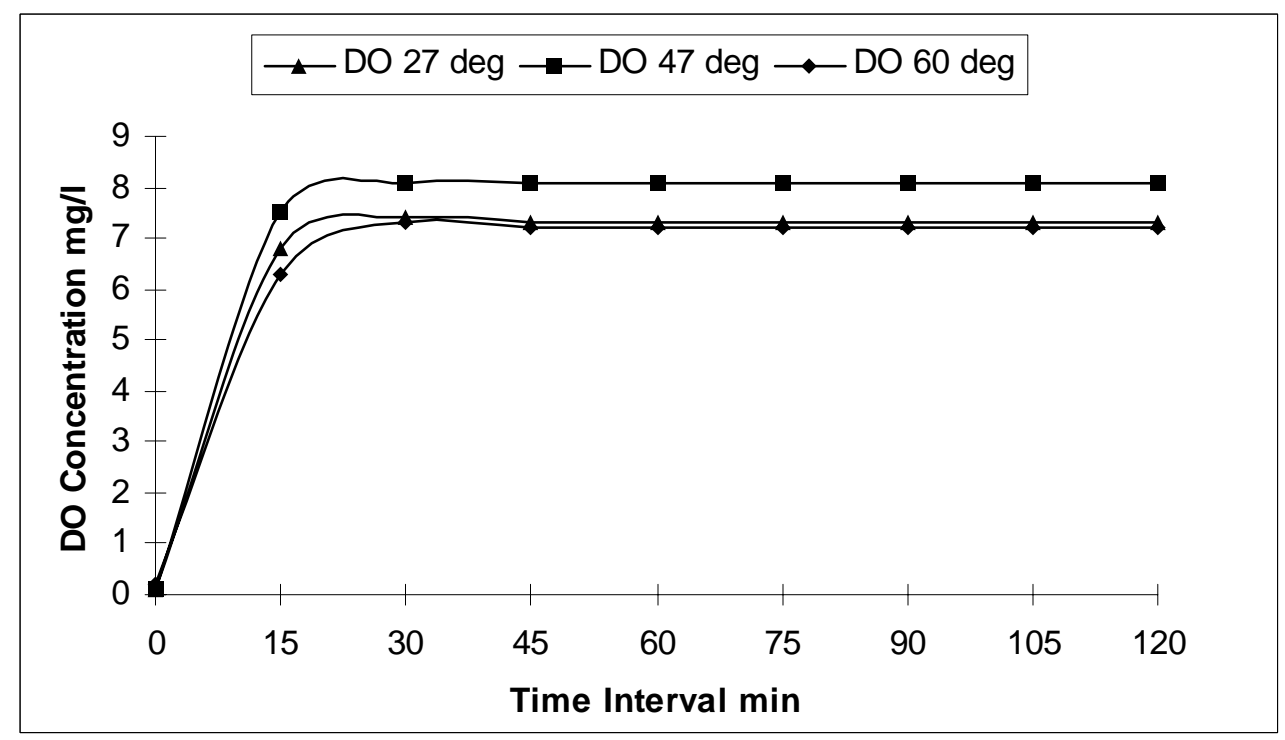

Figure 7. Variation of DO Vs Time for various angles of CBR, speed $48 \mathrm{rpm}$ and DOI- $5.5 \mathrm{~cm}$

4.5 Plot between $C_{(t+h)}$ and $C_{t}$ for determination of $K_{L} a$

As stated earlier, the plot between $C_{(t+h)}$ and $C_{t}$ will yield a straight line. The slope of the line is known and the value of $\mathrm{K}_{\mathrm{L}} \mathrm{a}$ is calculated. The time interval $\mathrm{h}$ is maintained as 15 minutes (Figure 9). The data obtained for different depth of immersion produced different curves. It is quite evident from the figure that the curve obtained for $5.5 \mathrm{~cm}$ depth of immersion, $48 \mathrm{rpm}$ speed, and 47 degree blade tip angle yielded maximum value of $\mathrm{K}_{\mathrm{L}}$ a. 


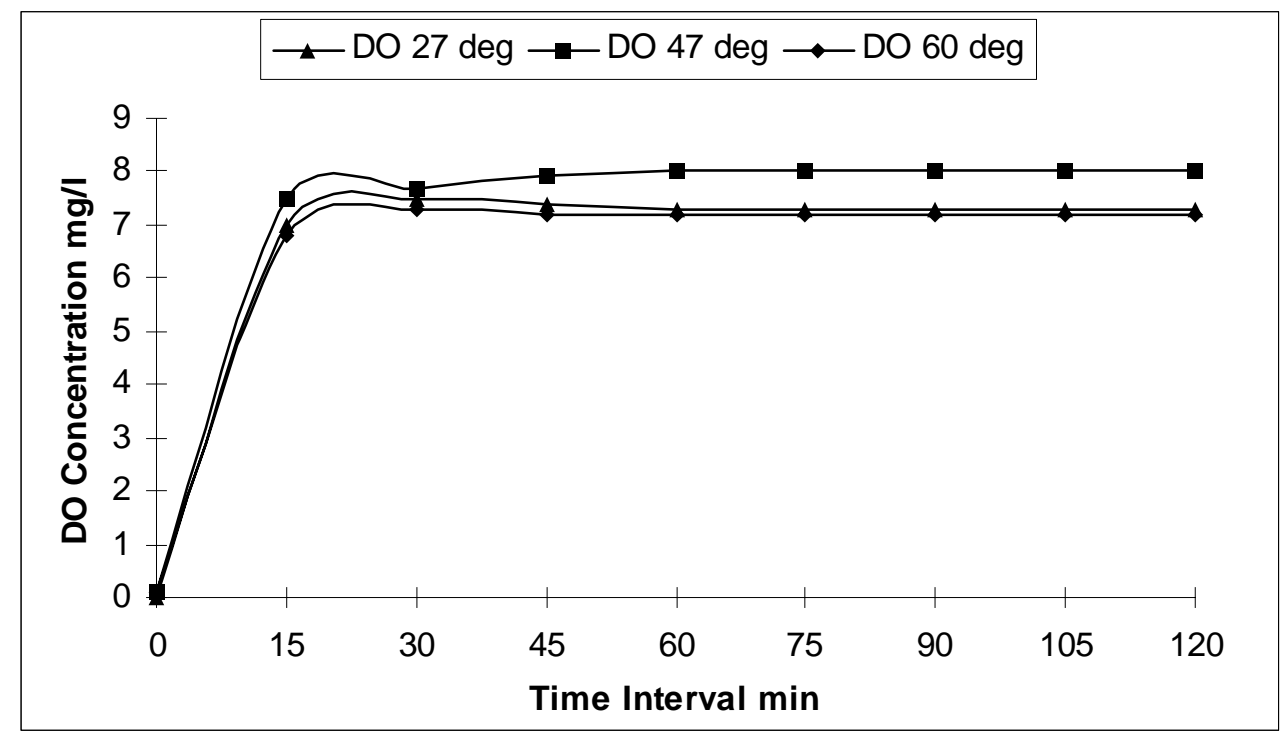

Figure 8. Variation of DO Vs Time for various angles of CBR, speed $60 \mathrm{rpm}$ and DOI-5.5 cm

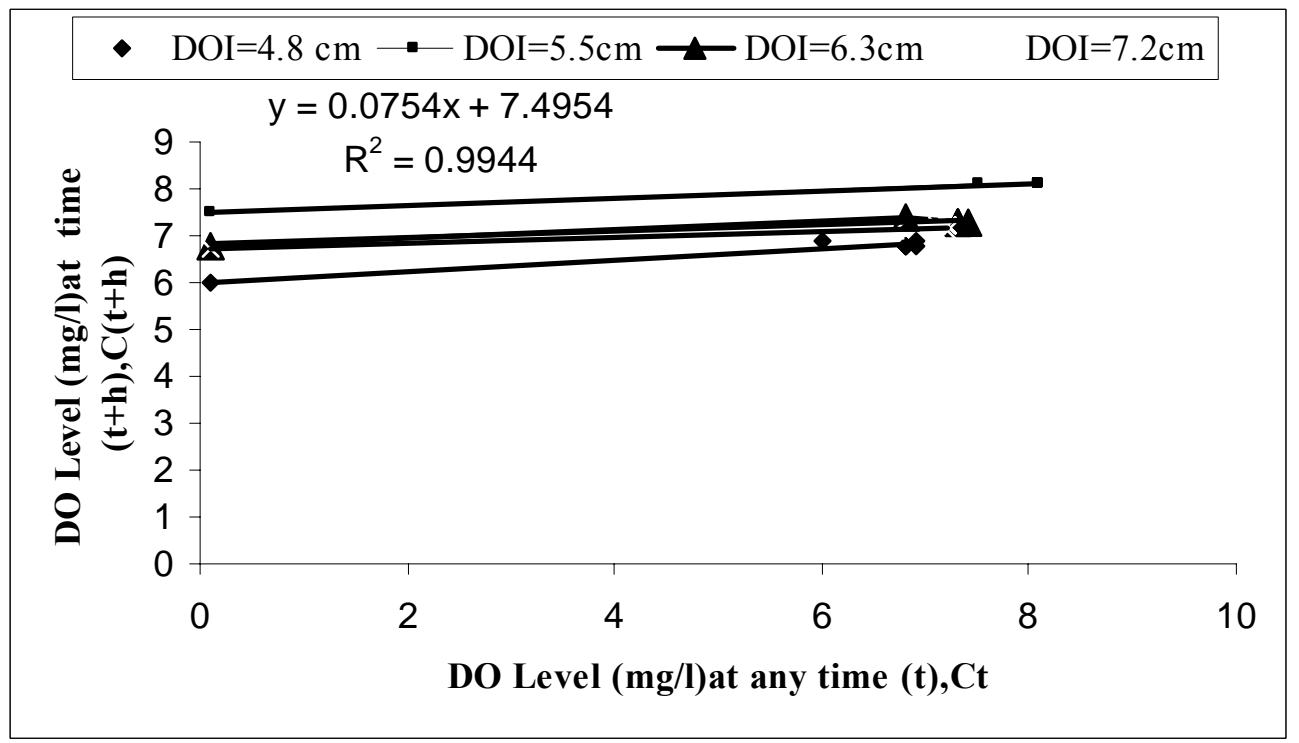

Figure 9. DO Level at time $(\mathrm{t}+\mathrm{h}) \mathrm{Vs}$ DO Level at time $\mathrm{t}$ for Determination of $\mathrm{K}_{\mathrm{L}} \mathrm{a}$

The variation in $\mathrm{K}_{\mathrm{L}} \mathrm{a}$ and power required are presented in Table1. It also suggests that depth of immersion is directly proportional to the power consumption. On the other hand the increase in $\mathrm{K}_{\mathrm{L}} \mathrm{a}$ is not that significant. As a golden mean, the value of $\mathrm{K}_{\mathrm{L}} \mathrm{a}$ is finally taken as $10.33 \mathrm{~h}^{-1}$ when the power required is $73.8 \mathrm{~W}$ and it is observed that the value of $\mathrm{AE}$ is the highest for these values, which is discussed later on.

Table 1.Variation of $\mathrm{K}_{\mathrm{L}} \mathrm{a}$ and Power with Depth of Immersion for $48 \mathrm{rpm}$ Speed

\begin{tabular}{|c|c|c|c|}
\hline S.No. & Depth of Immersion $(\mathrm{cm})$ & $\mathrm{K}_{\mathrm{L}} \mathrm{a}\left(\mathrm{h}^{-1}\right)$ & Power $(\mathrm{W})$ \\
\hline 1 & 4.8 & 8.414 & 69.9 \\
\hline 2 & 5.5 & 10.33 & 73.8 \\
\hline 3 & 6.2 & 10.58 & 93.5 \\
\hline 4 & 7.2 & 10.93 & 136 \\
\hline
\end{tabular}




\subsection{Variation in Aeration efficiency and $K_{L} a$ with respect to power}

Figure 10 describes the variations of $\mathrm{K}_{\mathrm{L}} \mathrm{a}$ and $\mathrm{AE}$ for various blades tip angles and speeds.

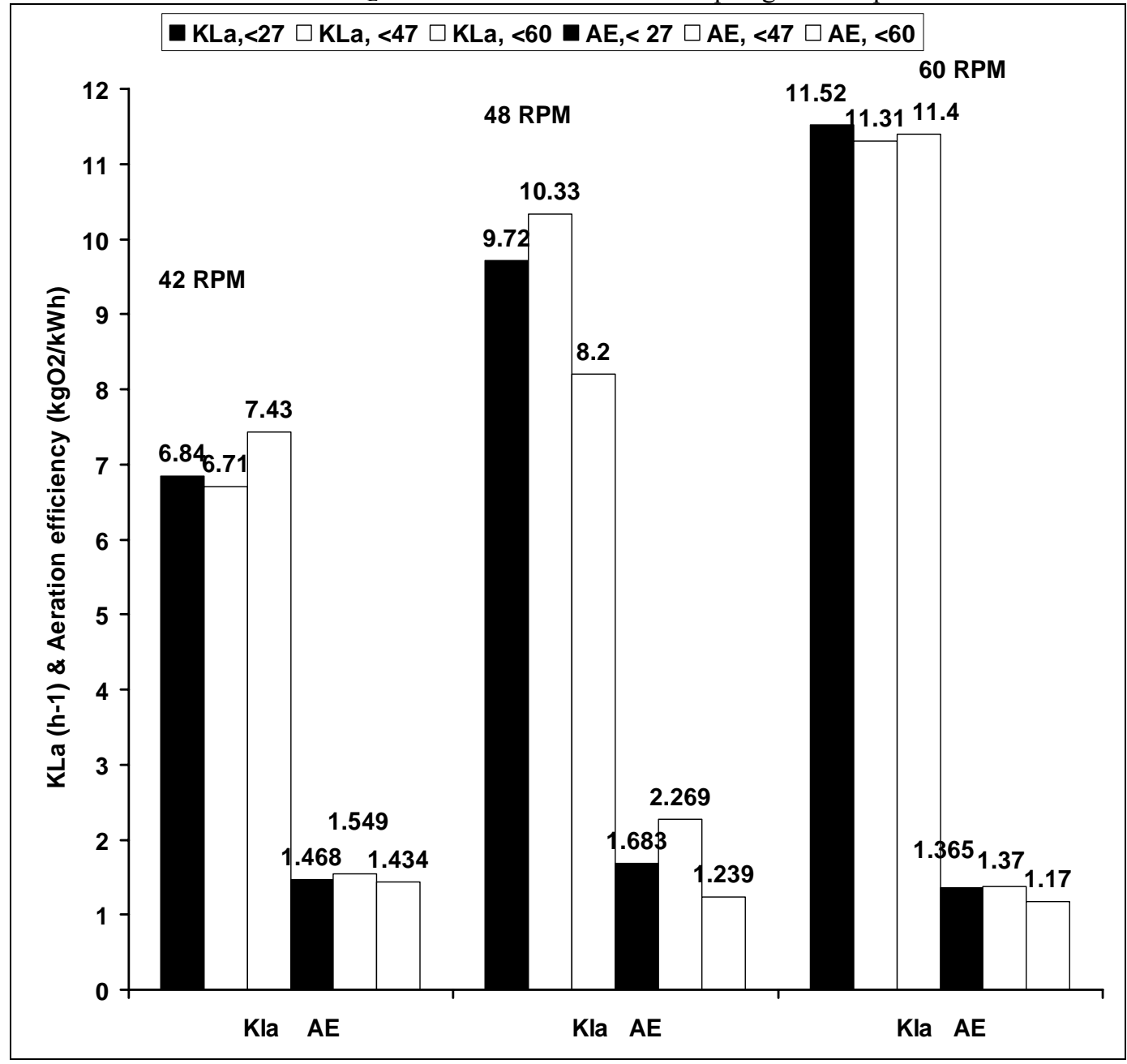

Figure 10. Variation in $\mathrm{k}_{\mathrm{L}} \mathrm{a}$ and $\mathrm{AE}$ with different blade angles and speeds

Out of the three configurations tested, it can be seen that at $48 \mathrm{rpm}$ and 47 degree blade tip angle, the optimum value of $\mathrm{K}_{\mathrm{L}} \mathrm{a}$ is observed to be $10.33 \mathrm{~h}^{-1}$ and recorded the highest value of $\mathrm{AE}$ that is $2.269 \mathrm{kgO}_{2} / \mathrm{kWh}$. This is because, the $\mathrm{AE}$ is the function of power and as stated earlier the power required increases with increase in speed and depth of immersion. Even though the values of $\mathrm{K}_{\mathrm{L}}$ a at $60 \mathrm{rpm}$ and 27, 47,60 degree blade tip angles are more than that of $48 \mathrm{rpm}$, the power required to attend the same is quite higher. Therefore, the AE values for above configuration and speed decreases drastically to $1.365,1.37,1.17 \mathrm{kgO}_{2} / \mathrm{kWh}$ as against the $\mathrm{AE}$ values of $1.683,2.269$ and $1.239 \mathrm{~kg} \mathrm{O}_{2} / \mathrm{kWh}$ at speed of $48 \mathrm{rpm}$.

The performance of aerator is better judged by a parameter known as aeration efficiency (AE), which is defined as amount of oxygen transferred per unit power under field conditions. Standard Aeration Efficiency of the aerator is defined as the amount of oxygen transferred per unit of power, at standard conditions of $20^{\circ} \mathrm{C}$ water temperature, $0 \mathrm{mg} / \mathrm{L}$ initial dissolved oxygen concentration, one atmospheric pressure, and clear tap water is used.

In the present study, the $\mathrm{AE}$ is observed to be $2.269 \mathrm{kgO}_{2} / \mathrm{kWh}$, which can be considered as field condition value. The water temperature was ranging from $24^{\circ} \mathrm{C}$ to $17.5^{\circ} \mathrm{C}$ during the experimentation. Secondly, after addition of sodium sulphite to the water, the initial concentration of water was sometimes observed to be on negative side, even though the prescribed quantity of sodium sulphite was added to the water as mentioned in the literature. (Kumar,1991). Therefore optimum AE expressed in terms of SAE i.e. at standard conditions. The SAE of aerator designed for present study comes out to be $2.95 \mathrm{KgO}_{2} / \mathrm{kWh}$. Table 2 shows the comparison of different aerators in terms of aeration efficiency.

Also in the present study, the inner surface of the ditch was coated with anticorrosive paint thereby minimizing the frictional losses. Therefore, it was observed that the flow of water in the ditch remains in turbulent stage from rotor1 to rotor 2 and subsequently loss of kinetic energy was also found to be less because of negligible frictional losses. Hence the efficiency is 
observed to be on the higher side as compared to Boyd (1998). More-over the limitation of the present study is that, it was a laboratory setup and therefore only few influencing parameters which are responsible for aeration efficiency were concentrated upon of out of many, otherwise, the standard aeration efficiency in the present case may have increased at least 1.3 times than the efficiency obtained presently.

Table 2. Comparison of different aerators in terms of standard aeration efficiency (SAE)

\begin{tabular}{|c|c|c|c|}
\hline Sr.No & Aerator type & $\begin{array}{c}\text { Standard aeration } \\
\text { efficiency } \\
\text { kg oxygen/kWh }\end{array}$ & References \\
\hline 1. & Taiwanese aerator & 1.17 & Boyd and Watten 1989; Boyd 1998 \\
\hline 2. & Japanese aerator & 1.03 & Boyd and Watten 1989; Boyd 1998 \\
\hline 3. & Auburn University & 2.25 & Boyd and Watten 1989; Boyd 1998 \\
\hline 4. & Present Study & 2.95 & \\
\hline
\end{tabular}

\subsection{Model}

In this paper attempts are made to correlate the data generated in the laboratory and the data calculated by using mathematical model. In this phenomenon, the author used two models. From the study of the data generated in laboratory, the attempts are made to identify the dependent and independent variables and by using Buckingham $\boldsymbol{\pi}$ theorem concept, these variables are correlated by developing dimensionally homogeneous equations.

$$
\begin{aligned}
& K_{L} a=0.000746\left[(N)^{1.768}\left(\frac{h}{D}\right)^{1.038}(\alpha)^{0.031}\right] \\
& P=0.0694\left[(N)^{2.062}\left(\frac{h}{D}\right)^{1.1412}(\alpha)^{0.1942}\left(K_{L} a\right)^{-0.1729}\right]
\end{aligned}
$$

where,
$\mathrm{K}_{\mathrm{L}} \mathrm{a}$ - overall oxygen transfer coefficient $\min ^{-1}$, $\mathrm{N}$ - Speed of aerator in rpm, $\mathrm{h} / \mathrm{D}$ - Ratio of depth of immersion to the diameter of aerator, $\alpha$ - Blade tip angle in degrees,
$\mathrm{P}-$ Power required in watts $(\mathrm{W})$.

The calculated values using the above models yielded good coefficient of determination $\left(\mathrm{R}^{2}\right)$ with the experimentally observed values which are in good agreement with standard error of estimation. A program in CPP is developed to interrelate the various influencing parameters mentioned above and are solved by multiple linear regression analysis method. Figure 11 and Figure 12 are the plots between the experimentally determined values and the calculated values from the model formulated for $\mathrm{K}_{\mathrm{L}} \mathrm{a}$ and power respectively.

It has been estimated that the simulation equations (4) and (5) predict the values of $\mathrm{K}_{\mathrm{L}} \mathrm{a}$ and power with an average standard error of estimation of 0.0164 and 7.66 respectively and with $R^{2}$ values of 0.9797 and 0.9892 respectively, when compared with experimentally determined values. Thus equations (4) and (5) are justifiable by taking into consideration all of the experimental errors themselves. Therefore, the above equations may be used with confidence for predicting the $\mathrm{K}_{\mathrm{L}} \mathrm{a}$ and power $(\mathrm{P})$ and can be considered as design equations for CBR aerator. The standard error of estimation for power happens to be large (7.66) because of the fluctuation in the power supply from the source. It was observed during the experimentation that the voltage fluctuation was from $210 \mathrm{~V}$ to $235 \mathrm{~V}$. To minimize the error for power measurement, the average readings were taken. 


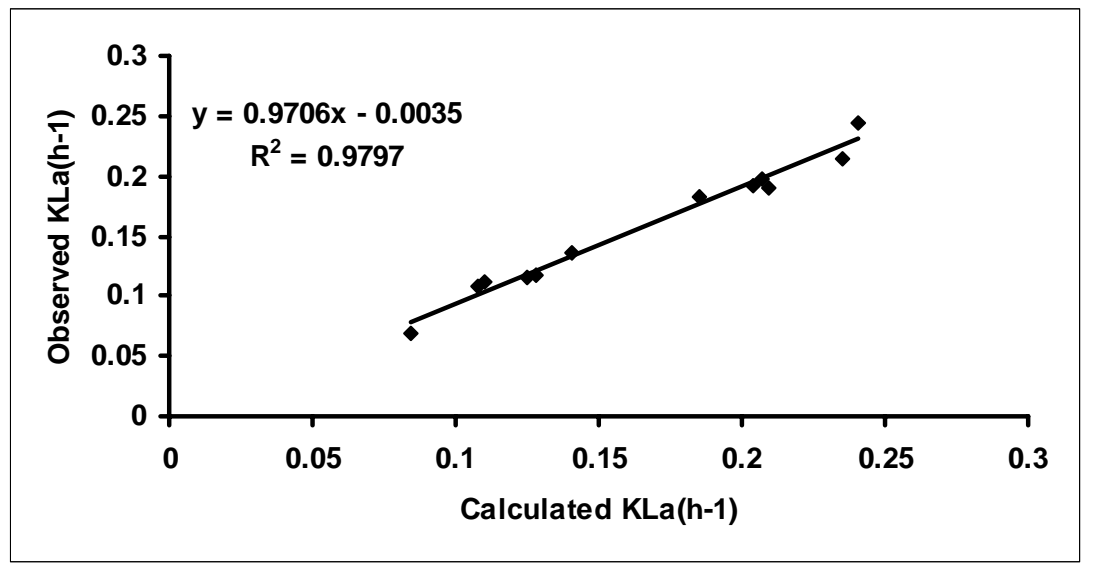

Figure 11. Relationship between observed and calculated values of $\mathrm{k}_{\mathrm{L}} \mathrm{a}$

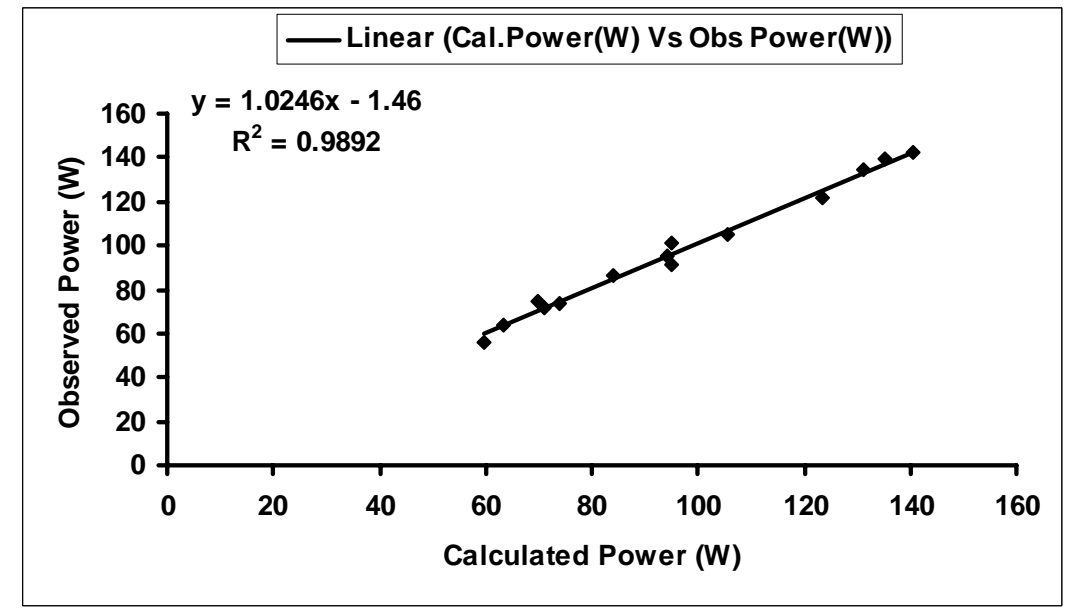

Figure 12. Relationship between observed and calculated values of Power (P)

\section{CFD Model}

The computational fluid dynamic model of an aerator used for treatment of waste water in oxidation ditch is a crucial part of this study. The results of this phase have a huge impact on the quality of the results obtained by experimental setup and the mathematical model developed. The main problem was to model the geometry of the aerator and the oxidation ditch. Actually the CFD part of this study is only to find out the correlation between the experimentally observed data and data generated by the CFD model and if the CFD model thus developed establishes good correlation with the observed data, it could be used to analyze the various parameters of the said system without fabricating the physical model. It is relatively trivial to draw the aerators in Gambit, but the problem is the overall number of elements. A single aerator has a number of groups with 12 blades each. Going further with the computation, it can be seen that in the oxidation ditch there are 2 aerators with 2 groups of 12 blades each. Overall, it is about 48 elements. The source of momentum in the ditch is the rotating aerators. To model the aerators the moving mesh option in fluent is used and the part of aerator that is submerged in the water is created.

\subsection{Modeling the Aerator}

The aerator can be modeled in different ways. The one that is finally used is the one phase, $3 \mathrm{D}$ model. To model the moving wall in fluent a volume with the shape of aerator was created and to define the constant velocity of it a user defined function is used. This way the cells that were source of momentum and were working like moving wall were created. There are low and high pressure regions before and after the rotor blades respectively, while a strong turbulence is created by the blades. Because it was decided to use a one phase model, instead of creating the whole aerator, only the part of the aerator under water level is used.

\subsection{Computational domain}

The model dimensions are $32 \times 12 \times 4.3 \mathrm{~cm}$ (length $\mathrm{x}$ width $\mathrm{x}$ height). Only the part of the aerator that is submerged in the water is modeled. The sides of the model are symmetrical boundary conditions. That way, we represent a number of groups of rotating blades. After meshing 2, 40,000 cells were created. 


\subsection{Setting up fluent}

Model:

Solver: 3 D, Pressure based, steady state

Viscous: Standard $\mathbf{k}-\boldsymbol{\varepsilon}$ (k-epsilon) fluid model

Material:

Water: Density $1000 \mathrm{~kg} / \mathrm{m}^{3}$

Viscosity $0.001003 \mathrm{~kg} / \mathrm{m}-\mathrm{s}$

Operating conditions: Gravity OFF

\subsection{Boundary conditions}

Inlet - pressure inlet - Pressure inlet with relative pressure equals 0 , instead of creating any flow it is providing as much water to the model as it is needed. This way aerator is the only source of momentum in the ditch.

Outlet - Pressure outlet - Similar to inlet pressure equals 0 . As inlet is not creating any flow, it is allowing water to go out of the model.

Side walls - symmetry - This way a very wide aerator which contains a number of blades groups is represented.

Bottom - wall - Roughness and other parameters are not important because they do not have influence on the flow very close to the aerator.

Free surface - symmetry - It is a standard method to represent a free surface.

Mesh: The tetrahedral 3-D mesh is used with mesh inflation applied at inner wall.

\subsection{Solving}

The case was computed after approximately 2000 iterations. In this research paper, an attempt is made to correlate the data generated in the laboratory with the model developed using Computational Fluid Dynamics. A series of simulation experiments were carried out on the CFD model developed.(Software ANSYS - FLUENT).

Flow governing equations used were, the Reynolds-averaged, Navier-Stokes equations, governing the three dimensional, steady, incompressible flow in the oxidation ditch.

The turbulence kinetic energy $k$, and its rate of dissipation $\varepsilon$, are computed from the transport equations for the Standard $\mathrm{k}-\varepsilon$ turbulence model.

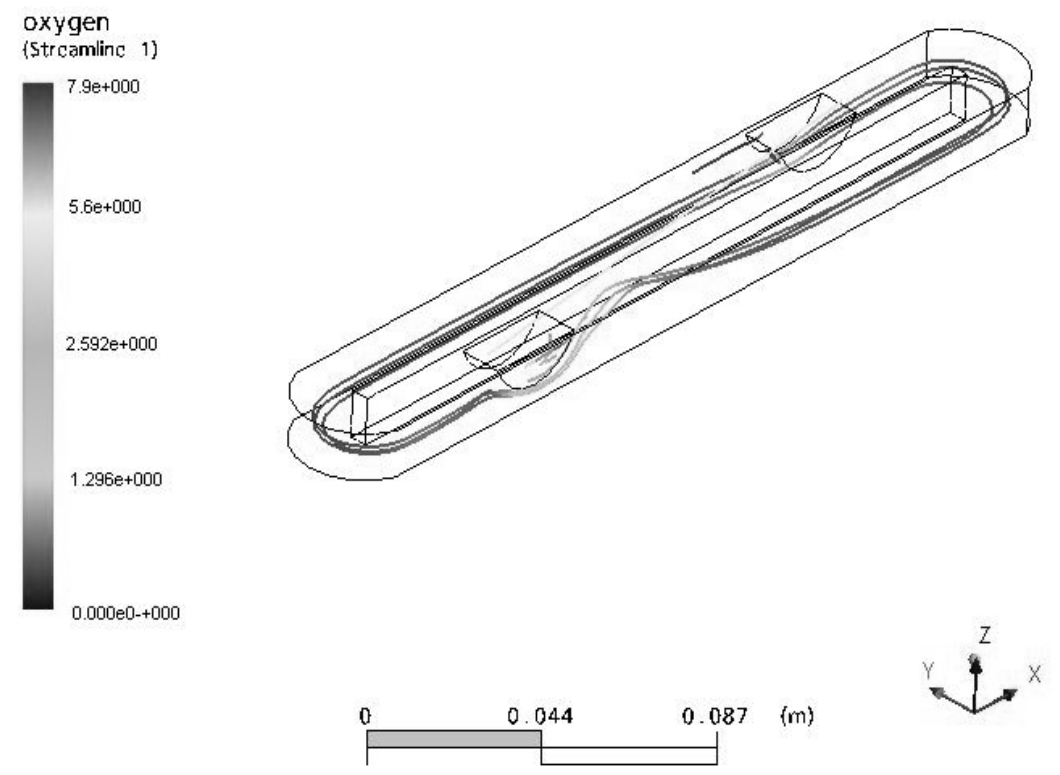

Figure 13: Streamlines of Oxygen Transfer in the water present in Oxidation Ditch

Figure 13 shows the variation in the oxygen transfer in different zones. It is clearly visible from the figure that oxygen transfer in the vicinity of aerators is quite predominant than that of other parts of the ditch.

The velocity profile was copied very close to the brush. It was done in order to minimize the influence of the flow in the ditch on the velocity profile. The copied values were measured $10 \mathrm{~cm}$ from the end of the rotors blade. As the turbulence is created, the dissolved oxygen (DO) transport was modeled using finite rate chemistry. The reaction was set to change DO in the water. 


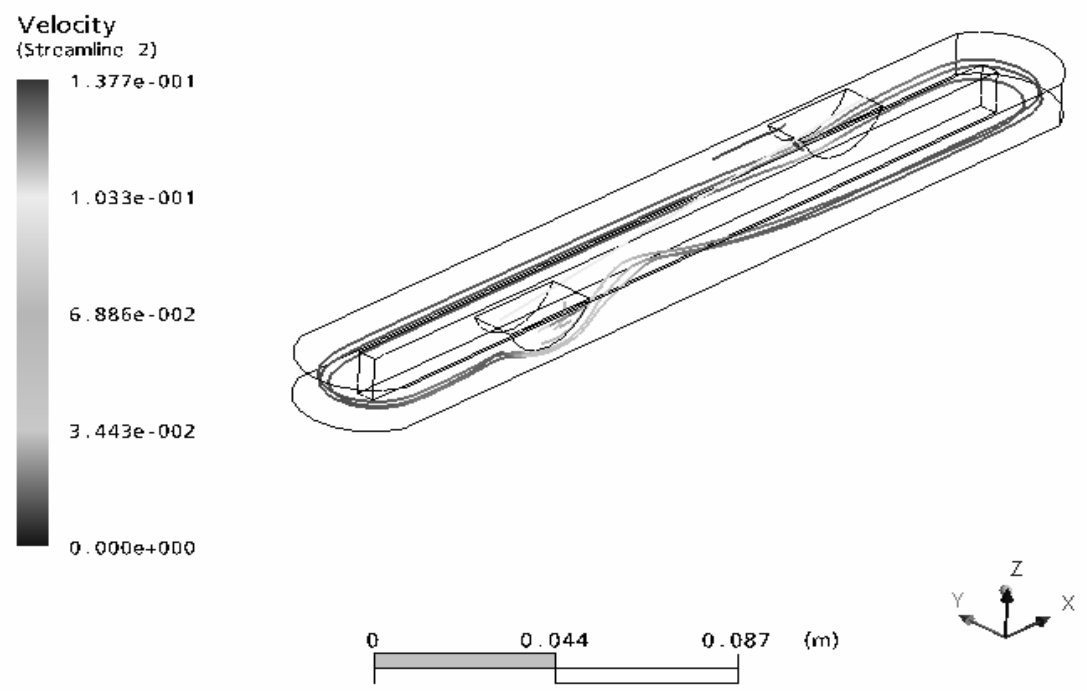

Figure 14. Streamlines of velocity of water flow in Oxidation Ditch

\subsection{Determination of $K_{L}$ a from CFD model}

A model with large amount of moving parts would be too complicated to be created and because of that it is sometimes impossible to solve to obtain accurate results. To overcome this situation simple logic was used. The velocity of flow in the oxidation ditch should be in the range of $0.25 \mathrm{~m} / \mathrm{s}$ to $0.6 \mathrm{~m} / \mathrm{s}$, (Abusam et al. 2002). During laboratory experimentation, the speed of the aerator was maintained at $36,42,48$ and $60 \mathrm{rpm}$, so that the above-mentioned velocity range could be satisfied. It was observed that the lower limit of velocity was satisfied by maintaining the speed at $36 \mathrm{rpm}$ and $0.5 \mathrm{~m} / \mathrm{s}$ velocity was observed at 60 $\mathrm{rpm}$. As the speed was increased beyond $60 \mathrm{rpm}$, there was rise in velocity but splashing of water from the ditch was observed, which is not tolerable, because oxidation ditch is used to treat the sewage.

It was a difficult task to model the brush rotation. It was, therefore decided to maintain the velocity of flow from $0.25 \mathrm{~m} / \mathrm{s}$ to 0.5 $\mathrm{m} / \mathrm{s}$ so that the speed of rotation of aerator could be determined from the experimental observations. Hereafter, the rise in DO

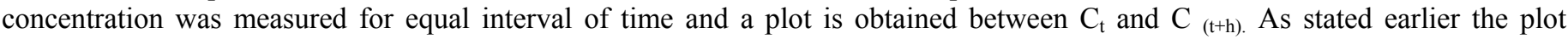
between $\mathrm{C}_{(\mathrm{t}+\mathrm{h})}$ and $\mathrm{C}_{\mathrm{t}}$ will yield a straight line. The slope of the line is known and the value of $\mathrm{K}_{\mathrm{L}} \mathrm{a}$ is calculated.

Figure 15 illustrates the relationship between the observed values of $\mathrm{K}_{\mathrm{L}}$ a and simulated values of $\mathrm{K}_{\mathrm{L}}$ a obtained from CFD model simulation. The $\mathrm{R}^{2}$ value of 0.9609 is obtained by plotting the above values against each other, which suggests that the CFD model and the simulation values thus generated are in good agreement with the experimental model and the observation recorded therein.

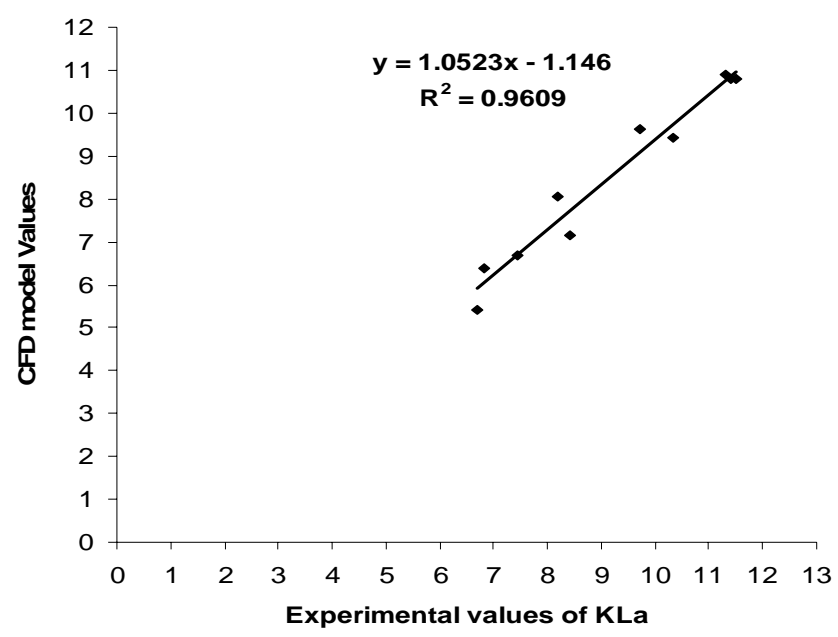

Figure 15. Relationship between Experimental values and CFD Model values 


\section{Conclusions}

The following conclusions are drawn from the study conducted:

1. The aerator configured in the present study was explicitly used for oxidation ditch process only, and the speed of rotation was in the range of $36 \mathrm{rpm}$ to $60 \mathrm{rpm}$. At $48 \mathrm{rpm}$ speed, 47 degree blade tip angle and $5.5 \mathrm{~cm}$ depth of immersion, the optimum value of aeration efficiency (AE) was obtained and was observed to be $2.269 \mathrm{kgO}_{2} / \mathrm{kWh}$. Secondly, with such a low speed, the back splash condition did not occur, as was observed in the case of Peterson E.L and Walkar M.B. (2002). Whereas the speed of paddle wheel aerator is of the tune of $135 \mathrm{rpm}$ (Moulick et al, 2005) and therefore, the occurrence of backsplash is very significant at higher speed using paddle wheel as an aerator.

2. The standard aeration efficiency of curved blade aerator was observed to be $2.95 \mathrm{kgO}_{2} / \mathrm{kWh}$.

3. It has been estimated that the simulation equations (4) and (5) predict the values of $\mathrm{K}_{\mathrm{L}} \mathrm{a}$ and power with $\mathrm{R}^{2}$ values of 0.9797 and 0.9892 respectively, when compared with experimentally determined values. Thus equations (4) and (5) are justifiable by taking into consideration all of the experimental errors themselves. Therefore above equations may be used with confidence for predicting the $\mathrm{K}_{\mathrm{L}} \mathrm{a}$ and power $(\mathrm{P})$ and can be considered as design equations for CBR aerator.

4. The model of the brush was created to understand the influence of an aerator on the flow velocity.

5. The oxygen transfer analysis gave all the results as were expected, but tracing the particles is not enough to model all the processes that takes place in the ditch, because the chemical, biological and physical processes have large influence on settling of particles.

6. A CFD model thus developed shows a good coefficient of correlation $\left(\mathrm{R}^{2}=0.9609\right)$ with the experimentally observed values and proves to be best-fit model with respect to oxidation ditch.

Finally, it can be concluded that aeration can be made more effective by optimizing various factors affecting it viz, speed of aerator, depth of immersion, blades angles etc. The CFD model developed leads to the improved quality of the waste-water treatment while saving money as required for running and maintaining it.

\section{Nomenclature}

$\mathrm{dc} / \mathrm{dt} \quad$ Rate of oxygen transfer in water.

$\mathrm{C}_{\mathrm{s}} \quad$ Saturation concentration of dissolved oxygen in water $(\mathrm{mg} / \mathrm{L})$.

$\mathrm{C}_{\mathrm{t}} \quad$ Concentration of dissolved oxygen in water at any time ' $\mathrm{t}$ '.

$\mathrm{h} \quad$ Time interval for taking observations ( $\mathrm{min}$ ).

$\mathrm{C}_{(\mathrm{t}+\mathrm{h})} \quad$ Concentration of dissolved oxygen in water after time $(\mathrm{t}+\mathrm{h})$.

DO Dissolved oxygen $(\mathrm{mg} / \mathrm{L})$

AE Aeration efficiency $\left(\mathrm{kgO}_{2} / \mathrm{kWh}\right)$.

SAE Standard aeration efficiency $\left(\mathrm{kgO}_{2} / \mathrm{kWh}\right)$.

DOI Depth of immersion (m).

CFD Computational fluid dynamics.

$\mathrm{K}_{\mathrm{L}} \mathrm{a}$ Overall oxygen transfer coefficient $\mathrm{min}^{-1}$,

$\mathrm{N} \quad$ Speed of aerator in rpm,

$\mathrm{h} / \mathrm{D} \quad$ Ratio of depth of immersion to the diameter of aerator,

$\alpha \quad$ Blade tip angle in degrees,

P Power required in watts (W).

\section{References}

Abusam.A., Keesman K.J., Spanjers H., Straten G. and Meinema. K. 2002. Effect of oxidation ditch horizontal velocity on the nitrogen removal process. European Water Management Online, EWA 2002.

APHA., 1985. Standard methods for the examination of water and wastewater, $15^{\text {th }}$ Ed., American Public Health Association, America Water Works Association, and Water Pollution Control Federation, Washington D.C.

Boyd C.E., Watten, B.J. 1989. Aeration systems in aquaculture. CRC Critical Reviews in Aquatic Science, Vol.1, No. 3, CRC press, pp. 425-472.

Boyd C.E., 1998. Pond water aeration systems. Aquacultural Engineering, Vol.18, pp.9-40.

Cancino, B., Roth, P., and Reuß, M., 2004. "Design of high efficiency surface aerators part 1. Development of new rotors for surface aerators." Aquacultural Engineering, Vol. 31, pp. 83-98.

Cancino B., 2004. Design of high efficiency surface aerators part 2. Rating of surface aerator rotors. Aquacultural Engineering, Elsevier, Vol.31, pp. 99-115.

Eckenfelder W.W., 1956. Process design of aeration system for biological waste treatment. Chemical. Engineering Progress, Vol.52, No 7, pp. 286-292. 
Metcalf and Eddy Inc., 2001. Waste water Engineering; Treatment disposal and reuse. $3^{\text {rd }}$ ed. Tata McGraw Hill, New Delhi India, 1200p.

Moulick S. Mal, B.C. Bandyopadhyay, S., 2005. Design characteristics of single hub paddle wheel aerator. Journal of

Environmental. Engineering, Vol.131. No. 8, pp. 1147-1154.

Horvath I., 1984. Modeling in the technology of waste water treatment, Pergamon press, Tarrytown, N.Y.

Kumar R., 1991. Oxygen transfer by mechanical aeration. M.E thesis, Dept. of Civil. Eng. University of Roorkee. Roorkee, India. Ognean T., 1993. Aspects concerning scale-up criteria for surface aerators. Water Research, Vol.27. No.3, pp.485-488.

Peterson E.L and Walkar M.B., 2002. Effect of speed on Taiwanese paddle wheel aeration. Aquacultural Engineering, Vol.26, pp. 129-147.

Rao A. R., 1999. Predication of reaeration rate in square, stirrers tanks. Journal of Environmental. Engineering, Vol.133, No 4, pp. $411-418$.

Rao A. R., Kumar, B., 2007. Neural modeling of square surface aerators. Journal of Environmental. Engineering, Vol.125, No. 3, pp. $215-223$.

Schmidtke N.W., Horwath, T., 1977. Scale-up methodology for surface aerated reaerators. Progress in Water Technology, Vol.9, pp. 477-493.

Thakre S.B., Bhuyar, L.B. and Deshmukh, S.J., 2008-a. Effect of different configurations of mechanical aerators on oxygen transfer and aeration efficiency with respect to power consumption. International Journal of Mechanical System Science and Engineering, WASET. Vol 2., No.2., pp. 100-108.

Thakre S.B., Bhuyar L.B. and Deshmukh S.J., 2008-b. Mathematical models for overall gas transfer coefficient using different theories and evaluating their measurement accuracy. International Journal of Chemical and Biomolecular Engineering. (WASET), Vol. 1, No. 4., pp. 203-207.

Thakre S.B., Bhuyar L.B. and Deshmukh S.J., 2009. Oxidation ditch process using curved blade as aerator. International Journal of Environmental Engineering, Science and Technology, Vol.6. No.1, pp.113-122.

Wesner G.M., Ewing, J. J., Lineck, T.S., Jr., and Hinrichs, D.J.1977. Energy conservation in municipal wastewater treatment. EPA-130/9-77-011, NTIS No PB81-165391, U.S. EPA Res., Washington, D.C.

Zlokarnik M. 1979. Scale up of surface aerators for waste water treatment. Advance Biochemical Engineering, Vol.11, pp.157-179.

\section{Biographical notes}

Dr. Lalit B. Bhuyar is Professor \& Head, Department of Mechanical Engineering, PRM Institute of Technology and Research, Badnera, Amravati (India). He has engaged in teaching and research activities since the last 20 years. His field of specialization is Thermal and Fluid Engineering. Dr. L.B. Bhuyar has published several papers in various national, international conferences and journals. He has guided 8 students for their Ph.D. work.

Prof. Shashank B. Thakre is working as a Professor in Mechanical Engineering Department, PRMIT \& R, Badnera, Maharashtra, India. He has done his research in the field of reutilization of domestic waste water by designing the aerators to be used in oxidation ditch. He has published 30 papers on various research areas such as renewable energy, environmental pollution and design, in national and international journals. Presently, he is focusing on experimentation and analysis of solar chimney power plant.

Dr. Nitin W. Ingole is Principal, IBSS College of Engineering, Ghatkheda, Amravati, Maharashtra, India. He has done his M.Tech. in Environmental Engineering. Dr. Ingole is engaged in Biomass energy development since the last 6 years. He has done extensive work on biogas development from aquatic plants and biomass. He has twenty and more international publication in national and international journals.

Received February 2009

Accepted February 2009

Final acceptance in revised form May 2009 